\title{
O PETIANO E O RETORNO AS COMUNIDADES POPULARES: COMPARTILHAMENTO ENTRE SABERES POPULARES E ACADÊMICOS NO ESPAÇO DE PRÉ-UNIVERSITÁRIOS POPULARES
}

\author{
TIERRE OTIZ ANCHIETA ${ }^{1}$ \\ MÔNICA HEITLING ${ }^{2}$ \\ TAINAN SILVA DO AMARAL ${ }^{3}$ \\ LISIANE COSTA CLARO ${ }^{4}$ \\ VILMAR ALVES PEREIRA ${ }^{5}$
}

\begin{abstract}
RESUMO: O presente trabalho tem como objetivo fazer uma reflexão sobre o(s) papel(is) dos espaços denominados cursos pré-universitários populares nas cidades de Rio Grande, São José do Norte, Santo Antônio da Patrulha e Capão do Leão, que se localizam no interior do Rio Grande do Sul. Essa ação ocorre por meio de uma parceria entre as escolas (as quais cedem o espaço físico para o curso), PAIETS(Programa de Auxílio ao Ingresso nos Ensinos Técnico e Superior) e PET(Programa de Educação Tutorial) Conexões de Saberes da Educação Popular e Saberes Acadêmicos, neles atuam graduandos dos cursos da Universidade Federal do Rio Grande - FURG oriundos de classe popular e até mesmo destes próprios cursos localizados em diferentes comunidades populares na cidade do Rio Grande e nas outras cidades. Os educadores na maioria das vezes retornam para esses contextos de atuação, pois acreditam na proposta e objetivo dos programas, dessa forma podem-se trabalhar os saberes populares presentes naquelas regiões e dialogá-los com os saberes acadêmicos que estes educadores/graduandos trazem para aquele contexto que também o faz pertencente desse ambiente. Desta forma, mantemos vivos todos os saberes populares de determinadas comunidades, não os substituindo por saberes acadêmicos, apenas correlacionando-os, com isso buscamos uma maior chance de ingresso para aqueles que almejam ingressar em um ensino superior de qualidade e gratuito independente das diversidades no sentido de condições socioeconômicas e ambientais. $O$ trabalho traz breves relatos das trajetórias e vivências que vem sendo construídas em alguns préuniversitários populares.
\end{abstract}

PALAVRAS-CHAVE: Comunidades Populares. Saberes Populares e Acadêmicos. Préuniversitário Popular.

1.Graduando do curso de Ciências Biológicas Licenciatura, tierreoa@hotmail.com, Universidade Federal do Rio Grande/Campus Carreiros, PET Conexões de Saberes da Educação Popular e Saberes Acadêmicos, FNDE.

2.Graduanda do curso de Pedagogia UAB, monicaheitling@yahoo.com.br, Universidade Federal do Rio Grande/Polo São José do Norte, PET Conexões de Saberes da Educação Popular e Saberes Acadêmicos, FNDE.

3.Graduando do curso de Artes Visuais Licenciatura, tainan_amaral@live.com, Universidade Federal do Rio Grande/Campus Carreiros, PET Conexões de Saberes da Educação Popular e Saberes Acadêmicos, FNDE.

4.Doutorando em Educação, lisianecostaclaro@ hotmail.com, Universidade Federal do Rio

Grande/Campus Carreiros, PPGEdu.

5.Doutor em Educação, vilmar1972@gmail.com, Universidade Federal do Rio Grande, Tutor PET Conexões de Saberes da Educação Popular e Saberes Acadêmicos, FNDE.

Revista PET Interdisciplinar e Programa Conexões/UFPA On-line. Vol. 01 - 2016.

Página 37 


\section{CONTEXTO}

O PAIETS (Programa de Auxílio ao Ingresso nos Ensinos Técnico e Superior), um programa de pesquisa, ensino e extensão da Universidade Federal do Rio Grande FURG, está presente em diversas comunidades da cidade de Rio Grande, RS. Dentre essas comunidades têm as que ainda vivem de pesca e agricultura, onde muitos não concluíram o ensino fundamental ou médio. Também se insere no centro da cidade e demais distritos.

Esse Programa trabalha, em grande parte, com cursos pré-universitários populares, os quais são acolhidos em instalações das escolas públicas presentes nesses espaços. Estes cursos são frequentados por educandos que, em alguns casos, cursam o terceiro ano do ensino médio nessas escolas ou arredores, trabalhadores do centro comercial da cidade que residem nessas comunidades, donas de casa que buscam ou ingressar em uma universidade pública ou concluir o ensino médio através do ENEM (Exame Nacional do Ensino Médio), trabalhadores do Polo Naval que há no porto da cidade e demais egressos do ensino médio.

Junto com o PIAETS atua o PET Conexões de Saberes da Educação Popular e Saberes Acadêmicos, onde tem por objetivo que pessoas de comunidades populares possam ter acesso a ensino de qualidade, através dos educadores que são oriundos dessas próprias comunidades e que ingressaram na Universidade, desta forma alicerçando a correlação entre os saberes acadêmicos e populares.

\footnotetext{
A transculturação é o fenômeno de troca entre os povos, noção esta que pode permear a relação atual entre comunidades populares e saberes acadêmicos. (GOMES, Edmilton, 2006. pg.45.)
}

Haja vista que os educadores que ali atuam, fazem ou fizeram parte daquele contexto e que atualmente estão inseridos na Universidade facilitando o contato e o diálogo entre educadores e educandos, mantendo, fazendo a manutenção dos tão importantes saberes populares com base nos saberes acadêmicos e construindo em coletivo diversas histórias.

\section{DESCRIÇÃO DA EXPERIÊNCIA}

O Programa atua em aproximadamente nove contextos na cidade de Rio Grande e em três outros contextos, dois em cidades vizinhas (Capão do Leão e São José do Norte) e outro em uma cidade em que há um dos polos da Universidade (Santo Antônio 
da Patrulha). O PAIETS atua nessas comunidades populares, buscando o ingresso e permanência de pessoas oriundas destes locais, de forma a reconhecer e trabalhar os saberes e culturas populares.

Para o desenvolvimento de um processo que realmente reconheça e trabalhe estas culturas e saberes populares próprios de cada contexto em que está inserido, é necessário um trabalho em conjunto com a comunidade, o curso e a universidade. $\mathrm{E}$ neste sentido entra a figura do Petiano, que está inserido nestas comunidades e contextos para ser uma ligação, um aliado entre comunidade e curso, curso, programa e universidade. Por meio do diálogo com a Universidade, a comunidade e o curso, o Petiano é mediador do diálogo deste tripé. O diálogo é de fato insubstituível neste momento onde é preciso que todos tenham liberdade para expor seus anseios e sonhos. É preciso o Petiano ali inserido, conversar e mediar estes momentos onde todos são autores daquilo que estão construindo.

Assim os bolsistas do Programa de Educação Tutorial - PET Conexões de Saberes da Educação Popular e Saberes Acadêmicos, que estão inseridos nos contextos fazem a intervenção entre os educandos, os coordenadores destes cursos préuniversitários e a Universidade, sendo que muitos dos coordenadores são os próprios bolsistas. Vale a pena reforçar que os bolsistas do PET Conexões de Saberes da Educação Popular e Saberes Acadêmicos são oriundos de cursos pré-universitários ou se identificam com essa luta, alguns participaram do curso como educandos, conseguindo ingressar na Universidade e retornaram ao curso como bolsistas ou até então coordenadores. Isto fortalece também o vinculo, o comprometimento e o diálogo que virá acontecer.

Os Petianos por serem, em muitas ocasiões das próprias comunidades onde agora atuam, enquanto bolsistas e graduandos da Universidade, conseguem dialogar com a comunidade. Essa aproximação é de extrema relevância, haja vista que o Petiano conhece os anseios e as dificuldades enfrentadas pelos moradores locais do bairro que acolhe o pré- universitário. Ao abarcar todos estes contextos culturais, históricos e sociais que não se podem ignorar para o curso, o Petiano reconhece a visão de um sujeito desta comunidade que nesse processo busca lutar pelo seu direito ao ensino, Nesse horizonte destacamos:

"O respeito, então, ao saber popular implica necessariamente o respeito ao contexto cultural. A localidade dos educandos é o ponto de partida para o conhecimento que eles vão criando o mundo. 'Seu' mundo, em última 
análise é a primeira e inevitável face do mundo mesmo.” (FREIRE, 1992. p.86).

Além disso, maior parte do Petianos é oriunda das camadas populares, os bolsistas são membros destas comunidades e antigos educandos dos cursos, os quais conseguem vivenciar de fato o respeito que Freire aponta. A união entre a comunidade, o curso e a universidade só ocorrem significativamente quando o Petiano consegue dialogar de forma aberta com todos os três espaços.

Nesse sentido que trazemos nossos breves relatos, contando experiências que narram nossa trajetória de educandos à educadores, não renunciando as nossas origens, muito pelo contrário, integrando-as a nossa cultura acadêmica.

"Fui educanda do curso acreditar que esta estabelecido na mesma escola publica e estadual no bairro Parque Marinha desde sua criação. Fui educando do Clube de Línguas onde aprendi a compreender e falar espanhol em um nível básico. As aulas eram dinâmicas, faziam com que conversássemos entre nós e contássemos histórias para os colegas para exercitar compreensão e oralidade.

Alguns anos após fui educando do Pré-CTI, preparatória para aqueles que estavam cursando a oitava série e pretendiam ingressar no Colégio Técnico Industrial, hoje IFRS, Instituto Federal do Rio Grande do Sul.

Em 2010 fui educanda do Pré-Enem, na turma se misturavam adolescentes do terceiro ano com senhores e senhores que não estudavam a mais de dez, vinte anos. E também por isso, além de qualquer preparação para a realização da prova, estava presente um sentimento de apoio e companheirismo, entre os educandos e também na relação dos educadores e da coordenação com os mesmos, o que impediu que alguns desistissem ao longo daquele ano.

No ano seguinte, aprovada para o Curso de Pedagogia retornei ao acreditar neste mesmo ano e assumi a coordenação do Pré-IFRS. Neste ano em que trabalhei com o Pré-IFRS trabalhamos para além dos conteúdos, tivemos rodas de conversa visitações a universidade, um simulado que imitava exatamente o processo de prova e momentos de confraternização para tranquilizá-los.” Mônica Heitling

"Durante o ano de dois mil e doze participei durante sete meses do curso préuniversitário popular que acontece em uma escola estadual no bairro que eu moro. Moro na Vila da Quinta, no quinto distrito do município de Rio Grande, extremo sul do Rio Grande do Sul. Cursava o ensino médio nessa escola no turno da manhã e ia para o 
curso no turno da noite".

O curso era constituído por alguns educandos que da mesma forma que eu cursavam o ensino médio e outros que trabalhavam no turno inverso ao curso; ministravam práticas educativas educadores que em sua maioria cursavam ainda a graduação em licenciatura e/ou bacharelado.

Com estes educadores pudemos ter um maior contato com a Universidade e diversos saberes acadêmicos; além de conhecer diversas novidades que há no mundo acadêmico.

Chegado ao fim do curso, prestei ao ENEM e ingressei no ano seguinte para o curso de Ciências Biológicas Licenciatura na Universidade Federal do Rio Grande. No ano posterior ingressando ao PET e retornando ao contexto onde fui educando, como coordenador e educador de biologia. Alimentando sonhos e mostrando para aqueles, que como eu e outros colegas meus podemos sim correlacionar os nossos saberes populares com os acadêmicos e nos tornarmos alguém melhor." Tierre Anchieta

"Em 2011, ano em que cursaria o $3^{\circ}$ ano do Ensino Médio, sou convidado a participar deste contexto do Pré-universitário Ousadia Popular, que acontece ainda hoje no Instituto Estadual de Educação São José na cidade de São José do Norte. Percebi enquanto educando que o que construíamos no curso se diferenciava do que vivia nas aulas do ensino médio. A educação popular, conceitos estes que vivenciávamos no curso, buscava uma participação muito maior dos educandos. Construíamos um ambiente de amizade, de diálogo e participação. Tínhamos as disciplinas comuns do ensino médio, mas construíamos diferente a aula que acontecia. Havia uma abertura para que cada educando fosse autor daquilo que aprendia junto ao educador e começo então a me familiarizar com aquele grupo, com o fato dos educadores não receberem um salário para estarem ali, tudo isso, percebo hoje, me ajudou a perceber que era algo diferente. No início de 2012, ingresso para a Universidade no curso de Artes Visuais Licenciatura e Bacharelado e retorno então ao Pré-universitário Ousadia Popular como educador. Enquanto educador percebo que toda prática educativa é construída não por um só sujeito, mas por todos aqueles que estão envolvidos na construção do saber, sejam eles educadores ou educandos. Considero isso um dos maiores aprendizados que tenho construído." Tainan Amaral.

\section{RESULTADOS/CONCLUSÕES}

Revista PET Interdisciplinar e Programa Conexões/UFPA On-line. Vol. 01 - 2016. Página 41 
Cada um de nós acompanha, em torno de três anos um curso popular, em uma comunidade específica, que detém suas particularidades, de linguagens, saberes, cultura e dificuldade que são por vezes inerentes e por vezes compartilhadas.

Em cada um destes contextos, e, em outros, que aqui não foram retratados, foi preciso, e ainda é, que se desenvolva uma prática diferenciada, que para além de uma preparação, mas que promova um encontro de conhecimentos e saberes locais e os saberes específicos, assim como políticos e culturais, dentre outros.

Neste sentido os educandos também participam de oficinas e debates sobre diversos assuntos, onde são incentivados a refletir sua realidade, se posicionar de forma crítica, não só para o que acontece no seu bairro, mas em sua cidade, estado e país também.

Cada uma destas comunidades onde os pré-universitários populares estão presentes, não apenas lutam por uma melhor chance de ingresso daqueles que já almejavam o ensino superior, mas intensificaram o interesse e o desejo pelo ingresso na universidade de muitos outros, independente de sexo, idade, religião e gênero, dentre outros.

Porém, mesmo com todos os benefícios que este compartilhar de vivencias e saberes, ainda se faz necessário pensar o motivo de que, mesmo hoje, quando a importância da educação, do ensino superior, está cada vez mais clara e é cada vez mais uma realidade e uma necessidade, ainda se faz necessário que existam intervenções para que as classes menos abastadas possam ter condições de lutar pelo seu direito de usufruir do mesmo.

\section{AGRADECIMENTOS}

Agradecemos ao FNDE; ao orientador Vilmar Alves Pereira; a Colaboradora Lisiane Costa Claro; a cada educando e educador; ao PAIETS (Programa de Auxílio ao Ingresso nos Ensinos Técnicos e Superior) e a cada membro do grupo PET - Conexões de Saberes da Educação Popular e Saberes Acadêmicos.

\section{REFERÊNCIAS}

FREIRE, Paulo. Pedagogia da Esperança: um reencontro com a pedagogia do oprimido. Rio de Janeiro: Ed. Paz e Terra, 1992. 
GOMES, Edmilton. Novos caminhos para o pré-vestibular da inclusão: uma análise do primeiro pré-vestibular promovido pelo Programa Conexões de Saberes na UFPE. In: SILVA, J.S.; BARBOSA, J.L.; SOUSA, A.I. (Orgs.). Comunidades populares e universidades: olhares para o outro. Rio de Janeiro, 2006. p 44-51. 